\title{
Suicide in prison and after release: a 17-year national cohort study
}

\author{
Anne Bukten ${ }^{1,2} \mathbb{D} \cdot$ Marianne Riksheim Stavseth $^{1,2} \mathbb{D}$
}

Received: 12 February 2021 / Accepted: 29 June 2021 / Published online: 24 August 2021

(c) The Author(s) 2021

\begin{abstract}
Background People in prison have an extremely high risk of suicide. The aim of this paper is to describe all suicides in the Norwegian prison population from 2000 to 2016, during and following imprisonment; to investigate the timing of suicides; and to investigate the associations between risk of suicide and types of crime.

Methods We used data from the Norwegian Prison Release study (nPRIS) including complete national register data from the Norwegian Prison Register and the Norwegian Cause of Death Register in the period 1.1.2000 to 31.12.2016, consisting of 96,856 individuals. All suicides were classified according to ICD-10 codes X60-X84. We calculated crude mortality rates (CMRs) per 100,000 person-years and used a Cox Proportional-Hazards regression model to investigate factors associated with suicide during imprisonment and after release reported as hazard ratios (HRs).

Results Suicide accounted for about $10 \%$ of all deaths in the Norwegian prison population and was the leading cause of death in prison (53\% of in deaths in prison). The CMR per 100,000 person years for in-prison suicides was 133.8 (CI 100.5-167.1) and was ten times higher $(C M R=1535.0$, CI 397.9-2672.2) on day one of incarceration. Suicides after release (overall $\mathrm{CMR}=82.8$, CI 100.5-167.1) also peaked on day one after release (CMR $=665.7$, CI 0-1419.1). Suicide in prison was strongly associated with convictions of homicide (HR 18.2, CI 6.5-50.8) and high-security prison level (HR 15.4, CI 3.6-65.0). Suicide after release was associated with convictions of homicide (HR 3.1, CI 1.7-5.5).

Conclusion There is a high risk of suicide during the immediate first period of incarceration and after release. Convictions for severe violent crime, especially homicide, are associated with increased suicide risk, both in prison and after release.
\end{abstract}

Keywords Prison $\cdot$ Suicide $\cdot$ Mortality $\cdot$ Criminal justice $\cdot$ Mental health $\cdot$ Release $\cdot$ Convictions

\section{Introduction}

Suicide is a major public health concern. Globally, nearly 800000 people die each year due to suicide, and suicide is the second leading cause of death among 15-29-year-olds [1]. People in prison have an extremely high risk of suicide; compared with people in the general population of the same sex and similar age, suicide rates of men are three times higher and for women, nine times higher [2]. Suicide

Anne Bukten

anne.bukten@medisin.uio.no

Marianne Riksheim Stavseth

m.r.stavseth@medisin.uio.no

1 Norwegian Centre for Addiction Research, University of Oslo, Oslo, Norway

2 Section for Clinical Addiction Research, Oslo University Hospital, Oslo, Norway is the single most common cause of death in prisons [3] and among the leading causes of death following release [4].

Various factors contribute to elevated suicide rates among people in prison. First, several well-established demographical and clinical risk factors are consistently overrepresented among prisoners upon arrival [3, 5-14]. In a recent review and meta-analysis, Zhong and colleagues found that the strongest clinical factors associated with suicide in prisons were suicidal ideation during the current period in prison, a history of attempted suicide, and current psychiatric diagnosis [14].

Additionally, the prison environment may contribute to an elevated risk of suicide [15], and the impact is likely magnified among people with individual risks. Having no social visits $[14,16]$ and factors such as isolation and single cell have been found to be associated with suicide in prisoners $[8,13,17]$.

Criminological factors are also associated with suicide in prisoners, and studies have found elevated suicide risk 
among people imprisoned for severe violent offences [13, $18]$, in particular homicide $[14,16]$ and according to remand status and serving a life- sentence [14]. In sum, factors associated with prisoner suicide include a range of demographical, clinical, environmental and criminological factors [3, 19].

Different time periods related to imprisonment and release have been associated with higher risk of suicide. The first weeks of imprisonment are associated with higher risks [20], especially among young males on remand [21]. Also, the period following release represents a vulnerable transition, involving a high risk of self-harm and suicide [22-24] and several studies have demonstrated high rates of suicides in the immediate period post release [7, 25, 26].

Prison suicide is a global problem, but its extent varies between countries. International studies comparing suicide rates have found that the Nordic countries have the highest prison suicide rates globally [2, 27]. In a recent metaanalysis investigating prion suicides in 24 counties, Norway peaked with 180 suicides per 100000 prisoners and as a country with a substantially increased risk of suicide amongst prisoners compared to the general population [2].

Suicides are preventable with timely, evidence-based, and often low-cost interventions [1]. However, for national responses to be effective, more information is needed to identify high-risk periods for suicide and modifiable risk and protective factors. The aim of this study is to: 1) describe all suicides in the Norwegian prison population from 2000 to 2016, in prison and after release, 2) to investigate the timing of suicides with regard to admission to prison and prison release, and 3) to investigate the association between types of crime and risk of suicide and criminal offences.

\section{Material and methods}

\section{Setting}

Norway is characterized by having low rates of imprisonment that aim at rehabilitation, and in which universal health care, including drug treatment, is provided. In 2020, the prison population rate per 100000 of the national population was 49 in Norway, compared to 639 in the US and 132 in the UK [28].

In 2019, Norwegian prisons had the capacity of 3550 prison beds and the mean number of inmates were 3218 [29]. Prison beds are spread over 49 prison units, a form of prison organization that allows most prisoners to preserve geographical closeness to friends and family. Norwegian prisons vary in size; the largest prison has a capacity of 400 people, while the smallest has only 15 .

All prisons are publicly funded and are categorized into high-security (almost two-thirds of prisons), low-security, or transitional housing units. Ideally, inmates begin serving their sentences in high-security prisons before being transferred to a prison with low security and subsequently to transitional housing units. However, most inmates are released from high-security units.

Of all releases from prison during 2018 , about $20 \%$ of the inmates were released after 30 days or less and about $85 \%$ were released within one year. Women constitute a minority in Norwegian prisons, with an annual proportion of approximately $6 \%$ [30].

\section{Design and population}

The design is a retrospective cohort study. We used data from the Norwegian Prison Release study (nPRIS). This cohort study includes all people imprisoned in Norway over a 17-year period (January $1^{\text {st }}, 2000$ until December $\left.31^{\text {st }}, 2016\right)$ collected from the Norwegian Prison Registry, including 114745 individuals contributing 187046 releases. The data were linked to the Norwegian Cause of Death Register using a unique 11-digit Personal Identification Number (PIN) given to all residents.

A total of 19140 individuals were excluded from the study cohort, resulting in a study population of 96856 individuals. The majority $(96.8 \%)$ of these exclusions were due to not having Norwegian PINs, which is a precondition for linking to registry data.

\section{Data sources}

The Norwegian Prison Registry (NPR) serves administrative and statistical purposes, and includes personal data on all persons imprisoned in Norway, including age, gender, convictions, and sentences [31]. The registry also includes date of admission and date of release, both for sentences served and time spent on remand. This includes a code describing the release circumstances, which differentiates between transfers to hospitals, rehabilitation institutions, deaths in prison and actual prison release. If a person is hospitalized during imprisonment, this will not be categorized as a release.

The Norwegian Cause of Death Register (NDR) includes complete death certificates reported by medical doctors after examination of the deceased. Death certificates are collected by the NDR at the Norwegian Institute of Public Health. All deaths are coded using the International Classification of Diseases, 10th revision (ICD-10) [32]. The NDR includes information about the underlying cause of death (the disease or injury which initiated the chain of morbid events leading directly to death) and immediate causes of death (the terminal event or complication present at the time of death) [33]. Information about where the person was found dead and the actual date of death is also included. The coverage 
and the completeness of the NDR is high; it comprises all Norwegian residents and include medical information on more than $98 \%$ of all deaths [33].

\section{Measures}

Causes of death were categorized as either natural or unnatural; natural causes were defined as ICD-10 chapters A through Q, while unnatural causes were defined as ICD-10 chapters V through Y.

In-prison suicides are defined by suicide-deaths occurring in prison. Persons who initiated "the suicide act" in prison, but died outside of prison, e.g. in the hospital, are not included. Suicides occurring any time after release are defined as 'after release'. We considered only suicides with fatal outcome, coded X60 through X84 according to the ICD-10.

Method of suicide were categorised as: Intentional selfpoisoning (X60-69), Intentional self-harm by hanging, strangulation and suffocation (X70), Intentional self-harm by firearm (X72-74), and "Other or unknown method" (X7677, X79, X81-84).

In the study cohort, most imprisonments included multiple convictions. "Main conviction" was defined as the most severe conviction. Types of crime were classified into ten groups. Nine were based on Statistics Norway's official crime statistics. In addition we included a separate group for homicide: (1) Property theft, (2) Other offences for profit, (3) Criminal damage, (4) Drug related offences, (5) Public order and integrity violations, (6) Sexual offences, (7) Traffic offences, (8) Violence and maltreatment, (9) Other offences [34] and (10) Homicide.

When calculating the CMRs for main convictions and Cox Proportional-Hazards models for suicides, the nine groups were collapsed into four groups due to small number of events per group: traffic offences, public order and integrity violations, criminal damage, property theft, other offences for profit and other offences were combined into one group named 'Public order and offences for profit'. Sexual offences and violence and maltreatment were combined into a group named 'Sex and violence'. Drug-related offences and homicide were kept as separate groups.

Prison security level at release was categorized into high security, low security and other. The category "other" includes transfers to hospital etc.

\section{Time at risk}

We defined two follow-up periods. In prison: The period between the first day of imprisonment and death, between first day of imprisonment and release, or between first day of imprisonment and the end of observation (December $31^{\text {st }}$, 2016). After prison: The period between release and death, from release to another imprisonment, or from release to the end of the observation period (December $31^{\text {st }}, 2016$ ). For the person contributing with multiple incarcerations and releases, all periods were included in the analysis.

101 deaths occurred during sentence but outside of prison (at a hospital etc.). Consequently, the date of release was set to the date of death and these deaths were excluded from the time-to-event analysis.

\section{Statistical analysis}

Descriptive statistics were conducted using IBM SPSS 26. Crude mortality rates (CMRs) and 95\% confidence intervals were calculated as number of deaths per 100000 person years (PY) [35].

To simultaneously evaluate the effect of several factors on timing of suicides we fitted Cox Proportional-Hazards models using $\mathrm{R}$ version 4.0.1. Separate models were fitted for in-prison and after release suicides. In the multivariate model for in prison suicides, age at incarceration (continuous), gender (binary; man/woman), type of imprisonment (binary; pre-trial detention/sentenced), security level (nominal: high, low, other), main conviction (nominal; see above) and first incarceration (binary; yes/no) were adjusted for. In the multivariate model for suicides after release we included age at release (continuous), gender (binary; man/woman), main conviction (nominal; see above), and the number of previous releases (continuous).

The proportional-hazards assumption was tested based on the Schoenfeld residuals [36] and our hypothesis did not violate the proportional-hazards assumption (data not shown). The coefficients were interpreted in terms of incidence hazard ratios (HR) with $95 \%$ confidence intervals. Separate models were fitted to suicides in prison and after release.

\section{Results}

Our cohort consisted of 96856 individuals (10.3\% females) contributing with 166767 incarcerations. Median age at first incarceration was 31 (IQR: 23-41). 68.5\% had one incarceration, while about $15 \%$ of the cohort had served 3 or more prison sentences (Table 1). Most imprisonments (75.4\%) were between $0-3$ months, while $6.2 \%$ were 12 months or more. In total, 8053 deaths were recorded in the cohort; of those, $42.5 \%$ were characterised as unnatural causes, including $811(10.1 \%)$ suicides (Table 1).

In total, 62 suicides occurred in prison and suicide was the leading cause of death in prison (53\% of in deaths in prison). Most suicides were committed by men (93.5\%), and most often $(87.1 \%)$ by means of hanging, strangulation and suffocation (X70). More than one fifth (21\%) of all in-prison 
Table 1 Demographic characteristic of the study population $(n=96$ 856) observed from 2000-2016

\begin{tabular}{|c|c|c|}
\hline Individuals & 96,856 & $\begin{array}{l}100 \% \\
(\%)\end{array}$ \\
\hline \multicolumn{3}{|l|}{ Age at first incarceration ${ }^{\mathrm{a}}$} \\
\hline$<20$ & 6598 & 6.8 \\
\hline $20-29$ & 38,648 & 39.9 \\
\hline $30-39$ & 23,743 & 24.5 \\
\hline $40-49$ & 16,334 & 16.9 \\
\hline $50-59$ & 8316 & 8.6 \\
\hline $60-69$ & 2713 & 2.8 \\
\hline$>70$ & 462 & 0.5 \\
\hline \multicolumn{3}{|l|}{ Gender $^{\mathrm{b}}$} \\
\hline Female & 9962 & 10.3 \\
\hline Male & 86,875 & 89.7 \\
\hline \multicolumn{3}{|l|}{ Number of incarcerations } \\
\hline 1 & 66,350 & 68.5 \\
\hline 2 & 15,746 & 16.3 \\
\hline 3 & 6305 & 6.5 \\
\hline 4 & 3257 & 3.4 \\
\hline $5+$ & 5198 & 5.4 \\
\hline Total deaths ${ }^{c}$ & 8053 & 100 \\
\hline Natural causes & 4,093 & 50.8 \\
\hline Unnatural cause & 3,425 & 42.5 \\
\hline Suicide & 811 & 10.1 \\
\hline Unknown/no cause given & 535 & 6.6 \\
\hline
\end{tabular}

${ }^{\mathrm{a}} 42$ persons missing age information

${ }^{\mathrm{b}} 19$ persons missing gender information

${ }^{\mathrm{c}}$ Natural cause: ICD-10 chapters A-Q, unnatural cause: ICD-10 chapters $\mathrm{V}-\mathrm{Y}$

suicides occurred within the first week and almost four fifths (77.4\%) were committed on pre-trail detention (Table 2).

In total, 749 suicides occurred after prison (9.4 of all deaths after release). Of all suicides occurring after release ( $n=749), 91.2 \%$ were committed by men. Common methods were hanging (44.0\%), self-poisoning (28.8\%) and intentional firearm (10.9\%) (Table 2).

Almost half of the people committing suicide in prison were convicted for severe violent crime, including violence and maltreatment $(33.9 \%)$ or a sexual offence $(12.9 \%)$. About one quarter were convicted for drug and alcohol offences $(25.8 \%)$. Half of suicides $(50.0 \%)$ were committed by people serving their first prison sentence, while one quarter $(24.2 \%)$ had four or more prior incarcerations (Table 3 ).

People committing suicide after release were most often convicted for drug and alcohol offences (34.6\%) and violence and maltreatment $(22.0 \%)$. About $70 \%$ of all committing suicide after release had only one prior prison sentence, while one fifth $(18.3 \%)$ had three or more previous incarcerations (Table 3 ).
The average crude mortality rate (CMR) in-prison suicide was 133.8 per 100000 prisoners. When stratifying by main conviction during the last prison sentence, the CMR for suicide among people convicted of homicide was 393.0 180.0 for sexual and violence offences and 109.8 for drug and alcohol offences (Fig. 1). For details, including confidence intervals, see Supplementary Table 1.

The average crude mortality rate (CMR) after-prison suicide was 82.8 per 100000 prisoners. When stratifying by main conviction during the last prison sentence, the CMR for suicide among people convicted of homicide was 212.4, 86.6 for drug and alcohol offences and 83.5 for sexual and violence offences (Fig. 1). For details, including confidence intervals, see Supplementary Table 1.

When stratifying the time-period after incarceration and release, the CMR after incarceration was 1535.0 at day 1 , 224.6 at week 1 , and 154.0 at months $2-6$. The CMR after release was 665.7 at day $1,296.9$ at week 1 and 110.6 at months 2-6 (Fig. 2). For details, including confidence intervals, see Supplementary Table 2.

The adjusted Cox regression model showed that in-prison suicide was associated with age at incarceration (HR 1.03, CI 1.01-1.06), being convicted of homicide (HR 18.20, CI 6.52-50.79), sexual and violent offences (HR 4.90, CI 2.14-11.24), drug and alcohol offences (HR 4.90, CI 1.26-7.56), pre-trail detention (HR 3.34, CI 1.78-6.27) and high-security unit (HR 15.36, CI 3.63-65.03) (Table 4a).

Risk of suicide after release was associated with being convicted of homicide (HR 3.05, CI 1.71-5.46), drug and alcohol offences (HR 1.25, CI 1.05-1.50) and number of prior incarcerations (HR 1.11, CI 1.06-1.15).

\section{Discussion}

Our study reports findings from all registered suicides among the total Norwegian prison population within a 17-year period. During 2000-2016, suicide was the leading cause of death during imprisonment and among the leading causes of death after release. The mean suicide rate was 133.8 per 100000 in prison, and 82.8 per 100000 after release. In comparison, the annual global age-standardized suicide rate of 11.4 per 100000 population in 2012 [1].

The immediate periods after imprisonment and after release both imposed a high risk of suicide; the suicide rate on day 1 was almost seven times higher than week 1 , and about ten times higher than months 2-6. Although the suicide rates after release were lower, we also found a similar trend related to time after release; the risk of suicide on day 1 after release was more than twice as high as week 1 after release, and six times higher than 2-6 months after release. 
Table 2 Characteristics of persons who committed suicide in prison $(n=62)$ and after release $(n=749), 2000-2016$

\begin{tabular}{|c|c|c|c|c|c|c|}
\hline & \multicolumn{2}{|c|}{ In prison } & \multicolumn{2}{|c|}{ After release } & \multicolumn{2}{|c|}{ Total } \\
\hline & $n$ & $\%$ & $n$ & $\%$ & $n$ & $\%$ \\
\hline \multicolumn{7}{|l|}{ Age at death } \\
\hline$<20$ & 1 & 1.6 & 7 & 0.9 & 8 & 1.0 \\
\hline $20-29$ & 19 & 30.6 & 195 & 26.0 & 214 & 26.4 \\
\hline $30-39$ & 23 & 37.1 & 230 & 30.7 & 253 & 31.2 \\
\hline $40-49$ & 11 & 17.7 & 191 & 25.5 & 202 & 24.9 \\
\hline $50-59$ & 6 & 9.7 & 95 & 12.7 & 101 & 12.5 \\
\hline $60-69$ & 1 & 1.6 & 26 & 3.5 & 27 & 3.3 \\
\hline$>70$ & 1 & 1.6 & 5 & 0.7 & 6 & 0.7 \\
\hline \multicolumn{7}{|l|}{ Gender } \\
\hline Female & 4 & 6.5 & 66 & 8.8 & 70 & 8.6 \\
\hline Male & 58 & 93.5 & 683 & 91.2 & 741 & 91.4 \\
\hline \multicolumn{7}{|l|}{ Type of suicide } \\
\hline Intentional self-poisoning (X60-69) & 3 & 4.8 & 216 & 28.8 & 219 & 27.0 \\
\hline $\begin{array}{l}\text { Intentional self-harm by hanging, strangula- } \\
\text { tion and suffocation (X70) }\end{array}$ & 54 & 87.1 & 332 & 44.0 & 386 & 48.0 \\
\hline Intentional self-harm by firearm (X72-74) & 0 & 0.0 & 82 & 10.9 & 82 & 10.1 \\
\hline Other (X71, X75-X84) & 4 & 6.5 & 119 & 15.9 & 123 & 15.2 \\
\hline \multicolumn{7}{|l|}{ Timing (after incarceration/after release) } \\
\hline On 1st day & 7 & 11.3 & 8 & 1.1 & & \\
\hline Within 1st week & 6 & 9.7 & 11 & 1.5 & & \\
\hline Within 2nd week & 7 & 11.3 & 13 & 1.7 & & \\
\hline Within 1st month & 5 & 8.1 & 14 & 1.9 & & \\
\hline Within 1st year & 31 & 50.0 & 130 & 17.4 & & \\
\hline \multicolumn{7}{|l|}{ Type of imprisonment } \\
\hline Pre-trial detention & 48 & 77.4 & & & & \\
\hline Sentenced & 14 & 22.6 & & & & \\
\hline \multicolumn{7}{|l|}{ Prison security level } \\
\hline High security & 53 & 85.5 & & & & \\
\hline Low security & 2 & 3.2 & & & & \\
\hline Other & 7 & 11.3 & & & & \\
\hline
\end{tabular}

Our results documenting a peak in suicides immediately after imprisonment are in line with prior international findings showing an increased risk during the first weeks and days in prison [20,37]. We also found an increased suicide risk among people on pre-trail detention and in high-security units supporting the existing international literature [38-41].

Although the suicide rates were lower after release, we found a doubled risk of suicide on day 1 post-release, compared to the rest of the week. With the exception of one study taking place in the northeast of Australia [24], our findings are in line with previous studies finding a peak in suicides after release [7, 20, 26]. The high overall suicide rate supports the idea that the transition to life outside prison is a period with substantially increased risk for premature death. Previous research has also suggested increased risks for overdose death during the immediate period post release $[4,24]$.
One main finding was the association between suicide both in prison and after release and being convicted of homicide: the risk of suicide in prison was more than 18 times higher among people convicted of homicide, adjusted for other factors. The link between violent crimes and suicide has also reported in other studies [13, 16-18]. In a recent systematic review and meta-analysis examining risk factors associated with suicide in prisoners, Zhong and colleagues found that several clinical, institutional, and criminological factors were associated with suicide among people in prison. Criminological factors included remand status, serving a life sentence, and being convicted of a violent offence, in particular homicide [14].

In line with Zhong's and colleagues recent study [14], pre-trail detention were also an important risk factor for inprison suicide in our cohort. 
Table 3 Criminal characteristics of persons who commit suicide in prison $(n=62)$ and after release $(n=749), 2000-2016$

\begin{tabular}{|c|c|c|c|c|c|c|}
\hline & \multicolumn{2}{|c|}{ In prison } & \multicolumn{2}{|c|}{ After release } & \multicolumn{2}{|c|}{$\begin{array}{l}\text { General prison } \\
\text { population }\end{array}$} \\
\hline & $n=62$ & $\%$ & $n=749$ & $\%$ & $n=96856$ & $\%$ \\
\hline \multicolumn{7}{|l|}{ Main conviction (last sentence) ${ }^{\mathrm{a}}$} \\
\hline Traffic offences & 0 & 0.0 & 59 & 7.9 & 8799 & 9.1 \\
\hline Public order and integrity violations & 0 & 0.0 & 27 & 3.6 & 3423 & 3.5 \\
\hline Drug and alcohol offences & 16 & 25.8 & 259 & 34.6 & 31,936 & 33.0 \\
\hline Sexual offences & 8 & 12.9 & 16 & 2.1 & 4808 & 5.0 \\
\hline Violence and maltreatment & 21 & 33.9 & 165 & 22.0 & 20,491 & 21.2 \\
\hline Homicide-incl. attempt & 10 & 16.1 & 12 & 1.6 & 712 & 0.7 \\
\hline Criminal damage & 0 & 0.0 & 12 & 1.6 & 610 & 0.6 \\
\hline Other offences for profit & 2 & 3.2 & 39 & 5.2 & 10,181 & 10.5 \\
\hline Property theft & 4 & 6.5 & 68 & 9.1 & 5342 & 5.5 \\
\hline Other offences & 1 & 1.6 & 19 & 2.5 & 2576 & 2.7 \\
\hline Missing & 0 & 0.0 & 73 & 9.7 & 7978 & 8.2 \\
\hline \multicolumn{7}{|l|}{ Number of incarcerations ${ }^{\mathrm{b}}$} \\
\hline 1 & 31 & 50.0 & 478 & 63.8 & 66,350 & 68.5 \\
\hline 2 & 8 & 12.9 & 134 & 17.9 & 15,746 & 16.3 \\
\hline 3 & 6 & 9.7 & 70 & 9.3 & 6305 & 6.5 \\
\hline 4 & 2 & 3.2 & 25 & 3.3 & 3257 & 3.4 \\
\hline $5+$ & 15 & 24.2 & 42 & 5.6 & 5198 & 5.4 \\
\hline
\end{tabular}

${ }^{a}$ Main conviction defined as the most serious type of crime in the last observed sentence in the study period ${ }^{b}$ Number of incarcerations during the study period
Fig. 1 Crude mortality rates per main conviction, by inprison suicides $(n=62)$ and suicides after release $(n=749)$, 2000-2016
In prison After release

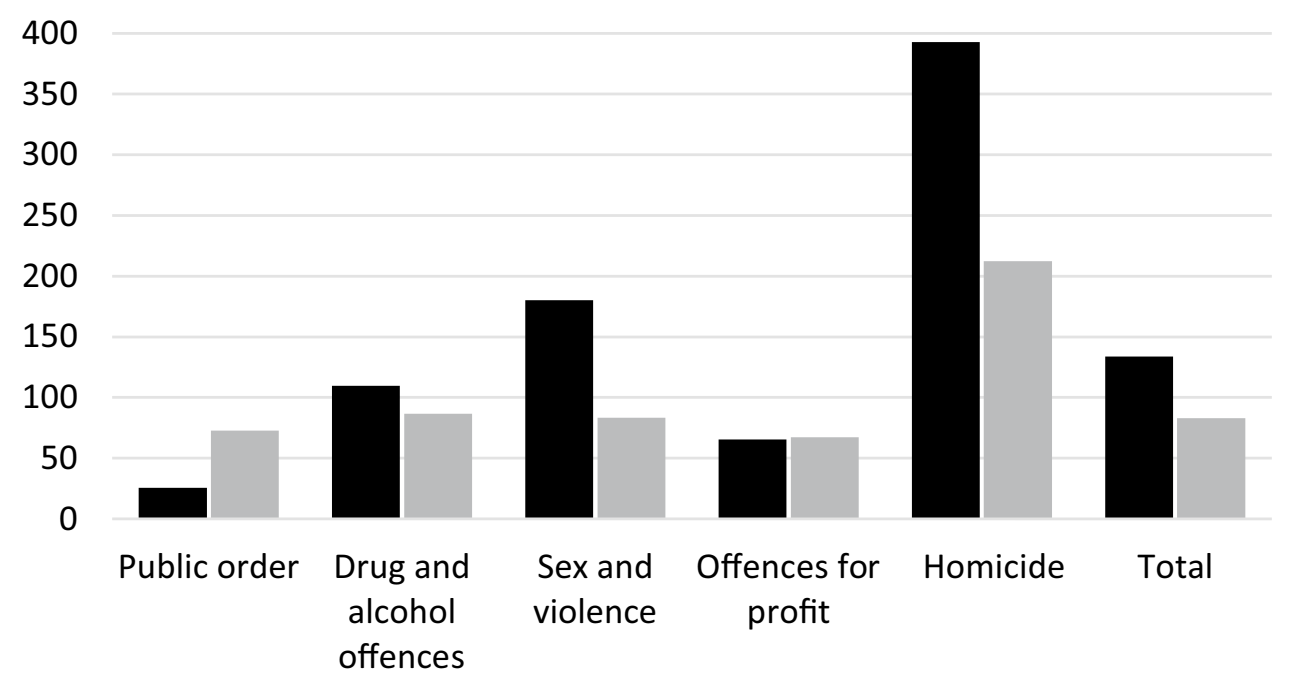

In a meta-analysis of prisoner suicide rates in 24 highincome countries in Europe, Australasia, and North America, Fazel and colleagues found that the rates of prisoner suicide were higher in countries where fewer individuals were imprisoned per 100000 members of the general population [2]. The authors proposed an explanation for this link related to the prisoners being more selected in terms of having sentences for more serious or violent offences and more likely to be suffering from mental illnesses, and thus more vulnerable. 
Fig. 2 Crude mortality rates for different time units after imprisonment or after release, by in-prison suicides $(n=62)$ and suicides after release $(\mathrm{n}=749)$, 2000-2016

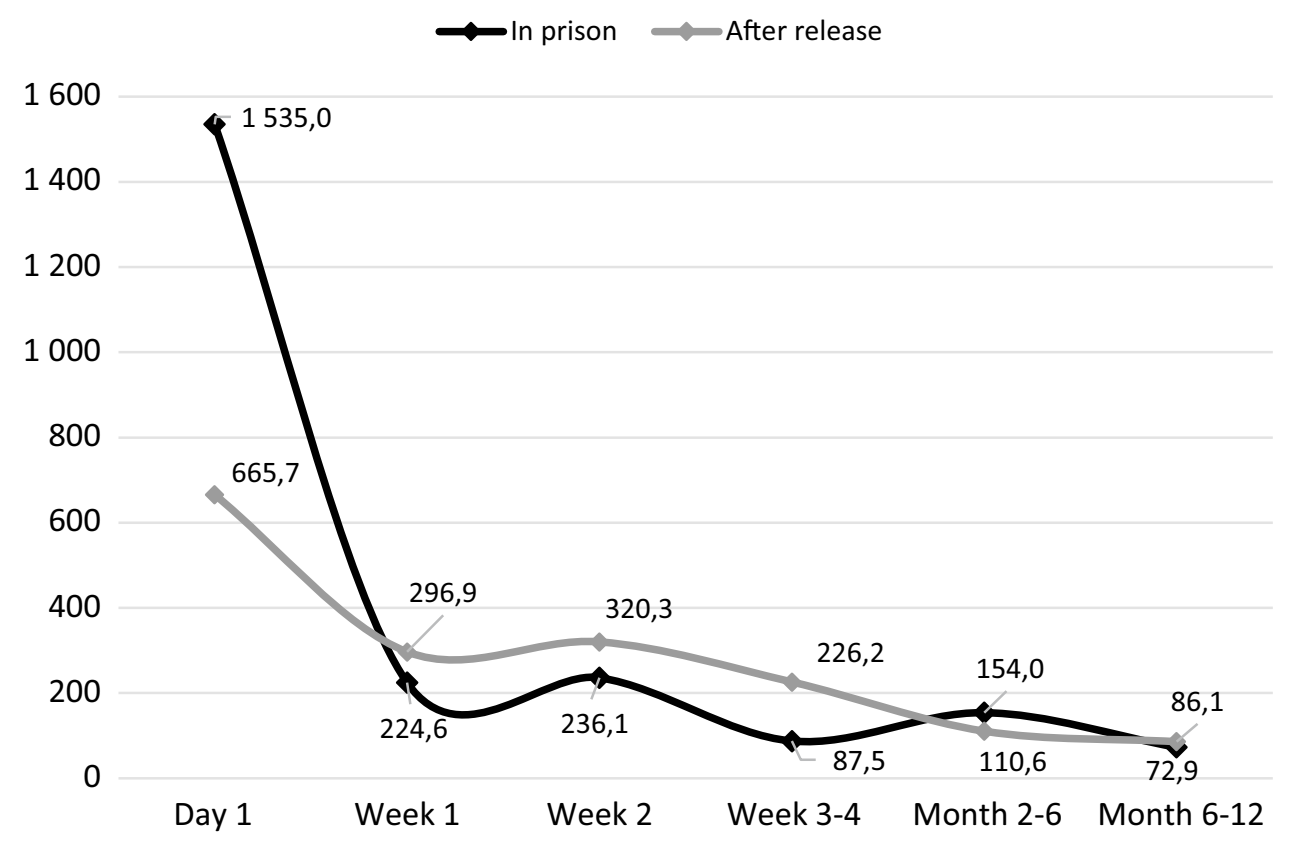

Table 4 Factors associated with suicides in the prison population. Separate Cox Proportional-Hazards models with associated hazard ratios (HRs) and 95\% confidence intervals (CIs) estimated for $\mathbf{a}$ in-prison suicides and $\mathbf{b}$ suicides after release

\begin{tabular}{|c|c|c|c|}
\hline (a) In prison model & HR & $95 \% \mathrm{CI}$ & $p$-value \\
\hline Age at incarceration & 1.03 & $(1.01-1.06)$ & 0.002 \\
\hline \multicolumn{4}{|l|}{ Gender (ref: female) } \\
\hline Male & 0.71 & $(0.30-2.30)$ & 0.712 \\
\hline \multicolumn{4}{|c|}{ Type of crime (ref: public order and offences for profit) } \\
\hline Drug and alcohol offences & 4.90 & $(1.26-7.56)$ & 0.014 \\
\hline Sex and violence & 4.90 & $(2.14-11.24)$ & 0.000 \\
\hline Homicide & 18.20 & $(6.52-50.79)$ & 0.000 \\
\hline \multicolumn{4}{|l|}{ First incarceration (ref: yes) } \\
\hline No & 0.84 & $(0.50-1.41)$ & 0.512 \\
\hline \multicolumn{4}{|c|}{ Type of imprisonment (ref: sentenced) } \\
\hline Pre-trial detention & 3.34 & $(1.78-6.27)$ & 0.000 \\
\hline \multicolumn{4}{|c|}{ Prison security level (ref: low) } \\
\hline High & 15.36 & $(3.63-65.03)$ & 0.000 \\
\hline Other & 5.43 & $(1.10-26.78)$ & 0.038 \\
\hline \multicolumn{4}{|l|}{ (b) After release model } \\
\hline Age at release & 1.00 & $(1.00-1.01)$ & 0.596 \\
\hline \multicolumn{4}{|l|}{ Gender (ref: female) } \\
\hline Male & 1.19 & $(0.89-1.58)$ & 0.239 \\
\hline \multicolumn{4}{|c|}{ Type of crime (ref: ref: public order and offences for profit) } \\
\hline Drug and alcohol offences & 1.25 & $(1.05-1.50)$ & 0.014 \\
\hline Sex and violence & 1.16 & $(0.95-1.41)$ & 0.135 \\
\hline Homicide & 3.05 & $(1.71-5.46)$ & 0.000 \\
\hline Number of releases & 1.11 & $(1.06-1.15)$ & 0.000 \\
\hline
\end{tabular}

\section{Strengths and limitations}

Using mandatory national registries is a major strength of the study. The datasets are linked using unique 11-digit 
identifiers assigned to all residents in Norway, minimizing the risk of linkage-biases. Moreover, all deaths are classified according to the most recent ICD criteria, and deathcategories are reported according to individual ICD codes, minimizing the risk of information bias.

Having a national cohort followed for 17 years enables stratified analysis, which is another major strength of the study. Our study is based on a large sample, and our results advance more precise day-by-day understanding of risk of suicide following incarceration and release. However, suicide is a rare event, and when analysing stratified groups, such as suicides per main conviction, some groups will have small numbers. This results in higher uncertainty, reflected in wide confidence intervals.

Another limitation is the lack of demographic and sociocultural variables in our dataset, in addition to information on mental health - factors that are associated with suicide in prisoners [8]. In Norway, one inmate per cell is most common. Sharing cells only happens occasionally and this information was thus not integrated in our dataset.

Misclassifications of causes of death may occur in registry data: it may be that some suicides might be classified as overdose deaths or accidents, causing an underestimation. However, Norwegian data has been assessed as having good validity and reliability for suicide classification [42].

Moreover, the number of suicides in prison may be somewhat underestimated due to how suicides are recorded in the databases. A person may have initiated a suicidal act in prison but dies in hospital later. Such mortalities will not be recorded as in-prison suicides in this article, as death occurred outside of prison.

\section{Conclusions and implications}

Our study showed that the immediate period after imprisonment and after release impose a high risk of suicide, especially among people convicted of homicide.

Suicide is a serious public health problem and the World Health Organization has prioritized reducing suicides in target 3.4 of the Sustainable Development Goals [43]. According to World Health Organization guidelines, the identification of high-risk groups is crucial to effective, public health suicide prevention approaches [3]. The peak in suicide on day one of incarceration highlights the importance of high alertness towards suicidal behaviour in recently admitted prisoners, and guidelines must therefore emphasize the need for risk assessment immediately after imprisonment [3]. In addition, being on pre-trial detention and serving in a high-security unit, should serve as important markers for increased risk.

Furthermore, our results highlight the critical period following release, adding to the literature addressing the vulnerable transition from prison to society. In order to bridge this gap, comprehensive provision of health care services is necessary throughout prison and after release alongside with social re-integration support for former prisoners.

Supplementary Information The online version contains supplementary material available at https://doi.org/10.1007/s10654-021-00782-0.

Acknowledgements We would like to thank the Norwegian Institute of Public Health and the Directorate of Norwegian Correctional Service for provision of data and helpful dialogue with regard to the registry data. A special thanks to Ashely Elizabeth Muller for a thorough readthrough of our manuscript.

Funding Open access funding provided by University of Oslo (incl Oslo University Hospital). This work was supported by [grant number HSØ 2019091].

\section{Declarations}

Conflict of interest The authors declare that they have no competing interest.

Ethical approval The study was approved by the Regional Committees for Medical and Health Research Ethics, Region South-East Norway, ref no 2012/140. The linkage was performed by the Norwegian Institute of Public Health, who prepared the files for analysis.

Data availability This population study was based on individual-level data from The Norwegian Prison Registry (held by the Directorate of Norwegian Correctional Service) and the Norwegian Cause of Death Register (held by the Norwegian Institute of Public Health). The ethical approval of this research project does not include permission to publicly share the raw data. Qualifying researchers can apply for access to relevant data with the Norwegian Institute of Public Health [44] and the Directorate of Norwegian Correctional Service [45] upon approval from the Regional Committees for Medical and Health Research Ethics [46].

Open Access This article is licensed under a Creative Commons Attribution 4.0 International License, which permits use, sharing, adaptation, distribution and reproduction in any medium or format, as long as you give appropriate credit to the original author(s) and the source, provide a link to the Creative Commons licence, and indicate if changes were made. The images or other third party material in this article are included in the article's Creative Commons licence, unless indicated otherwise in a credit line to the material. If material is not included in the article's Creative Commons licence and your intended use is not permitted by statutory regulation or exceeds the permitted use, you will need to obtain permission directly from the copyright holder. To view a copy of this licence, visit http://creativecommons.org/licenses/by/4.0/.

\section{References}

1. WHO. Preventing suicide: a global imperative. World Health Organization; 2014

2. Fazel S, Ramesh T, Hawton K. Suicide in prisons: an international study of prevalence and contributory factors. Lancet Psychiatry. 2017;4(12):946-52.

3. WHO. Preventing Suicide in Jails and Prisons. Geneva, Switzerland, Abuse DoMHaS; 2007. 
4. Bukten A, Stavseth MR, Skurtveit S, Tverdal A, Strang J, Clausen T. High risk of overdose death following release from prison: variations in mortality during a 15 -year observation period. Addiction. 2017.

5. Fazel S, Bains P, Doll H. Substance abuse and dependence in prisoners: a systematic review. Addiction. 2006;101(2):181-91.

6. Fazel S, Yoon IA, Hayes AJ. Substance use disorders in prisoners: an updated systematic review and meta-regression analysis in recently incarcerated men and women. Addiction. 2017.

7. Haglund A, Tidemalm D, Jokinen J, Langstrom N, Lichtenstein P, Fazel S, et al. Suicide after release from prison: a population-based cohort study from Sweden. J Clin Psychiatry. 2014;75(10):1047-53.

8. Fazel S, Cartwright J, Norman-Nott A, Hawton K. Suicide in prisoners: a systematic review of risk factors. J Clin Psychiatry. 2008;69(11):1721-31.

9. Bjorkenstam E, Bjorkenstam C, Vinnerljung B, Hallqvist J, Ljung R. Juvenile delinquency, social background and suicide-a Swedish national cohort study of 992,881 young adults. Int J Epidemiol. 2011;40(6):1585-92.

10. Thompson MP, Ho CH, Kingree JB. Prospective associations between delinquency and suicidal behaviors in a nationally representative sample. J Adolesc Health : Off Publ Soc Adolesc Med. 2007;40(3):232-7.

11. Webb RT, Qin P, Stevens H, Mortensen PB, Appleby L, Shaw J. National study of suicide in all people with a criminal justice history. Arch Gen Psychiatry. 2011;68(6):591-9.

12. Too LS, Spittal MJ, Bugeja L, Reifels L, Butterworth P, Pirkis J. The association between mental disorders and suicide: a systematic review and meta-analysis of record linkage studies. J Affect Disord. 2019;259:302-13.

13. Favril L, Wittouck C, Audenaert K, Vander LF. A 17-year national study of prison suicides in Belgium. Crisis. 2019;40(1):42-53.

14. Zhong S, Senior M, Yu R, Perry A, Hawton K, Shaw J, et al. Risk factors for suicide in prisons: a systematic review and metaanalysis. Lancet Pub Health. 2021;6(3):e164-74.

15. Hayes LMJJoCHC. National study of jail suicide: 20 years later. 2012; 18(3):233-45.

16. Duthe G, Hazard A, Kensey A, Shon JL. Suicide among male prisoners in France: a prospective population-based study. Forensic Sci Int. 2013;233(1-3):273-7.

17. Fruehwald S, Matschnig T, Koenig F, Bauer P, Frottier P. Suicide in custody: case-control study. B J Psychiatry : J Mental Sci. 2004;185:494-8.

18. Radeloff D, Stoeber F, Lempp T, Kettner M, Bennefeld-Kersten K. Murderers or thieves at risk? offence-related suicide rates in adolescent and adult prison populations. PLoS One. 2019;14(4):e0214936.

19. Marzano L, Hawton K, Rivlin A, Smith EN, Piper M, Fazel S. Prevention of suicidal behavior in prisons. Crisis. 2016;37(5):323-34.

20. Kucmanic MJ, Gilson TP. Suicide in jail: a ten-year retrospective study. Acad Forensic Pathol. 2016;6(1):109-13.

21. Hammerlin Y. Fengselslivet som en livstruende byrde (Only in Norwegian). Suicidologi. 2018;23(3).

22. Binswanger IA, Stern MF, Deyo RA, Heagerty PJ, Cheadle A, Elmore JG, et al. Release from prison-a high risk of death for former inmates. N Engl J Med. 2007;356(2):157-65.

23. Kariminia A, Law MG, Butler TG, Levy MH, Corben SP, Kaldor $\mathrm{JM}$, et al. Suicide risk among recently released prisoners in New South Wales, Australia. Med J Aust. 2007;187(7):387.

24. Spittal MJ, Forsyth S, Pirkis J, Alati R, Kinner SA. Suicide in adults released from prison in Queensland, Australia: a cohort study. J Epidemiol Community Health. 2014;68(10):993-8.

25. Spittal MJ, Forsyth S, Borschmann R, Young JT, Kinner SA. Modifiable risk factors for external cause mortality after release from prison: a nested case-control study. Epidemiol Psychiatr Sci. 2019;28(2):224-33.
26. Pratt D, Piper M, Appleby L, Webb R, Shaw J. Suicide in recently released prisoners: a population-based cohort study. Lancet. 2006;368(9530):119-23.

27. Fazel S, Grann M, Kling B, Hawton K. Prison suicide in 12 countries: an ecological study of 861 suicides during 2003-2007. Soc Psychiatry Psychiatr Epidemiol. 2011;46(3):191-5.

28. WPB. International Centre of Prison Studies 2020 [cited 2018 11.08.2020]. Available from: http://www.prisonstudies.org/.

29. The Norwegian Correctional Services, Annual statistics 2019 (Only in Norwegian). Oslo, Norway2019.

30. The Norwegian Correctional Services, Annual statistics 2018 (Only in Norwegian). Oslo, Norway: Kriminalomsorgen 2018.

31. The Norwegian Correctional Services (Only in Norwegian: Kriminalomsorgens sentrale datasystemer) 2015 [cited 2021 13.07]. Available from: http://www.kriminalomsorgen.no/kriminalom sorgens-sentrale-datasystemer.4454702.html.

32. WHO. The ICD-10 Classification of mental and Behavioural Disorders. Clinical descriptions and diagnostic guidelines: World Health Organization; 19931993.

33. Pedersen AG, Ellingsen CL. Data quality in the causes of death registry. Tidsskrift for den Norske laegeforening : tidsskrift for praktisk medicin, ny raekke. 2015;135(8):768-70.

34. Statistics Norway. Classification of type of offence 2020 [Available from: https://www.ssb.no/en/klass/klassifikasjoner/146.

35. Rothman K, Greenland, Lash T. Modren Epidemiology: Lippincott Williams \& Wilkinis; 20082008.

36. Cleves M, Gutierrez RG, Gould W, Marchenko YV. An Introduction to Survival Analysis Using Stata. 3rd ed. Texas: Stata Press; 2010. p. 2010.

37. Austin AE, van den Heuvel C, Byard RW. Prison suicides in South Australia: 1996-2010. J Forensic Sci. 2014;59(5):1260-2.

38. Petersen J, Kunze S, Thiel A, Fiedler G, Briken P, Puschel K. Deaths in Hamburg prisons 1996-2012 - recommendations on suicide prevention in prison custody. Arch Kriminol. 2017;239(3-4):73-86.

39. Radeloff D, Lempp T, Herrmann E, Kettner M, Bennefeld-Kersten K, Freitag CM. National total survey of German adolescent suicide in prison. Eur Child Adolesc Psychiatry. 2015;24(2):219-25.

40. Humber N, Webb R, Piper M, Appleby L, Shaw J. A national case-control study of risk factors for suicide among prisoners in England and Wales [corrected]. Soc Psychiatry Psychiatr Epidemiol. 2013;48(7):1177-85.

41. Opitz-Welke A, Bennefeld-Kersten K, Konrad N, Welke J. Prison suicides in Germany from 2000 to 2011. Int J Law Psychiatry. 2013;36(5-6):386-9.

42. Tøllefsen IM, Helweg-Larsen K, Thiblin I, Hem E, Kastrup MC, Nyberg U, et al. Are suicide deaths under-reported? Nationwide re-evaluations of 1800 deaths in Scandinavia. BMJ Open. 2015;5(11):e009120.

43. Nations U. Sustainable Development Goals. United Nations, S-1018, New York, NY 10017. USA: United Nations Department of Public Information; 2019.

44. The Norwegian Institute of Public Health Oslo, Norway2021 [cited 2021 13.07]. Available from: https://www.fhi.no/en/.

45. The Norwegian Correctional Service Norway2021 [cited 2021 13.07]. Available from: https://www.kriminalomsorgen.no/?cat= 536003.

46. The Regional Committees for Medical and Health Research Ethics Norway2021 [cited 2021 13.07]. Available from: https://rekpo rtalen.no/\#hjem/home.

Publisher's Note Springer Nature remains neutral with regard to jurisdictional claims in published maps and institutional affiliations. 